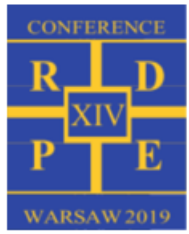

\title{
Two-Phase Ferrofluid Systems: Surfactants and Thermal Properties of Iron Oxide Nanofluids for Condensation
}

\author{
Daniel Zabek ${ }^{1,}{ }^{*}$, Andrzej Grzebielec ${ }^{1}$, Luca Cmok $^{2}$, Patricija Hribar B oštjančič ${ }^{2,3}$ and Alenka M ertelj² \\ ${ }^{1}$ Institute of H eat Engineering, W arsaw University of Technology, ul. N owowiejska 21/25, 00-665 W arsaw, \\ *Daniel.Zabek@itc.pw.edu.pl, Poland. \\ ${ }^{2}$ Department of Complex Matter, Jožef Stefan Institute, Jamova Cesta, 39, 1000 Ljubljana, Slovenia. \\ ${ }^{3}$ Jožef Stefan International Postgraduate School, J amova Cesta 39, 1000 L jubljana, Slovenia.
}

\begin{abstract}
Evaporation heat transfer with ferrofluids has the potential to improve heat and mass transfer compared to conventional two-phase systems. The ferromagnetic nanoparticles which control the rheology and heat transfer properties of the ferrofluid, must be coated with a dispersing agent, also referred to as a surfactant, to prevent particle agglomeration. This paper compares ferromagnetic iron-oxide particles coated with fatty acid, polymeric and hydrophobic surfactants after undergoing evaporation and condensation. The outcome was measured by assessing the dispersion of the ferrofluid after condensation. The fatty acid surfactants demonstrated the best dispersion after condensation proving temperature stability.
\end{abstract}

\section{Introduction}

Heat and mass transfer is becoming the limiting factor of modern electrical components (e.g. CPUs, solid state memory), energy transformation (e.g. rectifiers and inverters), energy generation (e.g. fuel cells) and energy storage technologies (e.g. batteries). In these fields, extreme thermal loads of up to $1000 \mathrm{~W} \cdot \mathrm{cm}^{-2}$ are expected and therefore, a need for an immediate breakthrough in cooling technology research has been identified [1]. One promising approach in resolving these limitations is the use of ferrofluids. Ferrofluids have, compared to pure solvents or water, solid ferromagnetic particles dispersed in a liquid carrier fluid. The dispersed particles can change the rheology and heat transfer properties of the fluid and can be used for various applications such as e. g. in magnetic transformer oil for electrical insulation and cooling [2], in lubrication and establishing thermal contact in shaft bearings in turbines, [3] as seals and for damping [4]. One particular advantage with ferrofluids is that the solid ferromagnetic particles dispersed in thecarrier fluid usually have a high thermal conductivity compared to the base liquid carrier fluid [5]. However, in ferrofluids the interaction between the solid particles dispersed in the liquid carrier fluids critical to the ferrofluid mixture. In order to prevent particle agglomeration and to maintain a repelling force between the particles, the particles must be coated with a stabilizing dispersing agent, also referred to as a surfactant. The surfactant are molecules which modify the surface properties of the ferromagnetic particles in order to obtain a stable suspension or colloid [6]. The repelling force between the particles is maintained despite strong magnetic fields or high temperatures. However, under high temperatures the liquid carrier fluid experiences boiling. This boiling phase transition is complex because it separates the solid particles from the gaseous. On the other hand, this phase transition can be favourable because the evaporation process has the potential to be much more effective than conventional thermal conductivity, due to the high level of thermal energy needed for evaporation. The possibility to cycle the ferromagnetic particles through an evaporation and condensation phase is primarily dependent on the surfactant maintaining the repelling force between the solid particles.

Three different classes of $\mathrm{Fe}_{3} \mathrm{O}_{4}$ iron-oxide(magnetite) ferrofluids with different surfactants were sourced from Ferrotech (US) and compared as follows: EM G 1200 Fatty acid, EMG 1300 - Polymeric and EMG 1400 Hydrophobic [7].W hen the ferrofluid is heated, the carrier fluid evaporates and a sludge of solid particles and surfactant remains. When the ferrofluid is cooled, the carrier fluid condenses and ideally mixes with the particle sludge. The aim of this experiment was to demonstrate and visualise the mixing behaviour of the condensed carrier fluid with the ferrofluid particles. Hence, this paper presents preliminary experimental results on ferrofluid evaporation and condensation demonstrating the possibility of two-phase ferrofluid applications by comparing the effects a fatty acid, a polymeric and a hydrophobic-surfactant have oniron oxide nanoparticles in a $\mathrm{n}$-H eptane carrier fluid. These preliminary results enable further investigation into powerful ferrofluid cooling systems capable of dissipating extreme thermal loads and reducing the cooling device size. 


\section{Governing equations experimental procedures}

Thermal conductivity, evaporation and condensation has been extensively studied with solids and fluids providing sufficient theoretical and experimental evidence for most engineering applications. The proposed ferrofluid evaporation experiment takes place under constant thermal boundary conditions where the heat flow $Q$ [W] is defined as $[8,9]$ :

$Q=-k A \frac{\Delta T}{\Delta x}=\frac{\Delta U}{\Delta t}+\frac{W}{\Delta t}$

and where $k\left[\mathrm{~W} \cdot \mathrm{m}^{-1} \mathrm{~K}^{-1}\right]$ is the thermal conductivity of the material, $A\left[\mathrm{~m}^{2}\right]$ the surface area, $\Delta T[\mathrm{~K}]$ the available temperature difference, $\Delta x[\mathrm{~m}]$ the thickness, $\Delta U[\mathrm{~J}]$ change in internal energy and $W[\mathrm{~J}]$ work done by the thermodynamic system. When maximising the heat flow in equation 1 , it is crucial to improve the thermal conductivity $k$ of the material. The effective thermal conductivity determining the heat transfer in a ferrofluid suspension $k_{\text {suspension }}\left[\mathrm{W} \cdot \mathrm{m}^{-1} \mathrm{~K}^{-1}\right.$ ] is based in the thermal conductivity of the carrier fluid $k_{\text {liquid }}\left[\mathrm{W} \cdot \mathrm{m}^{-1} \mathrm{~K}^{-1}\right]$ and the thermal conductivity of the suspended ferromagnetic particles $k_{\text {solid }}\left[\mathrm{W} . \mathrm{m}^{-1} \mathrm{~K}^{-1}\right.$, and is generally correlated by the following expression for a two component ferrofluid mixture as follows[10]:

$k_{\text {suspension }}=k_{\text {liquid }} \frac{1+0.5\left(\frac{k_{\text {solid }}}{k_{\text {liqud }}}\right)-\Phi\left(1-\left(\frac{k_{\text {solid }}}{k_{\text {liqud }}}\right)\right.}{1+0.5\left(\frac{k_{\text {solid }}}{k_{\text {liqud }}}\right)+0.5 \Phi\left(1-\left(\frac{k_{\text {solid }}}{k_{\text {liqud }}}\right)\right.}$

where $\Phi[-]$ is the volume phase fraction of the solid. Assuming that the solid particles are coated in a surfactant and heated in series under uniaxial heating conditions, the thermal conductivity for the solid component in equation 2 is defined as [11]:

$\frac{1}{k_{\text {solid }}}=\frac{1}{k_{\text {surfactant }}}+\frac{1}{k_{\text {particles }}}$

with proportional components for particles content and surfactant in dry particles. Most common ferrofluids have solid phase fractions between $1-10 \%$ including the surfactant component. Hence, based on equation 2 the thermal conductivity of most ferrofluids is only slightly higher with the suspended particles than the thermal conductivity of the carrier fluid, and only moderately improves with increasing particle concentration, and overall does not improve the thermal conductivity of the fluid significantly [12]. According to equation 1 , in order to improve the heat transfer of a ferrofluid, evaporating the liquid carrier fluid requires a substantial amount of thermal energy to change from the liquid phase to the gas phase. The corresponding thermal evaporation enthalpy $\Delta H_{v a p}[\mathrm{~J}]$ is defined as [8]:

$\Delta H_{\text {vap }}=\Delta U_{\text {vap }}+W$

and the evaporation change in energy is $\Delta U_{v a p}[\mathrm{~J}]$. Substituting equation 4 into equation 1 enables to maximise the heat flow with ferrofluids using thermal evaporation. For the proposed evaporation experiment, dry ferrite particles (Ferrotech - US) were disperse in nHeptane at a concentration of $1 \%$ by weight and sonicated for 10 minutes [7]. The iron-oxide particles have an average particles size of $10 \mathrm{~nm}$ and a thermal conductivity of $2.4 \mathrm{~W} \cdot \mathrm{m}^{-1} \cdot \mathrm{K}^{-1}$ [13]. The surfactants (fatty acid-, polymeric- and hydrophobic) are initially assumed to have an approximate thermal conductivity of $1 \mathrm{~W} . \mathrm{m}^{-}$ ${ }^{1} . \mathrm{K}^{-1}$ [14]. For the $\mathrm{n}$-Heptane carrier fluid a thermal conductivity of $0.14 \mathrm{~W} \cdot \mathrm{m}^{-1} \cdot \mathrm{K}^{-1}$ is assumed[15]. Essentially, the effective thermal conductivity increases linearly to the change in the weight phase fraction of the iron-oxide particles added [16]. Subsequently, the sonicated $1 \%$ ferrofluid suspension was transferred into a $500 \mu \mathrm{m} \times 100 \mu \mathrm{m}$ square and $70 \mathrm{~mm}$ long sealed closed volume glass capillary.

\section{Results and discussion}

According to equation 2, the thermal conductivity was calculated for particle weight fractions between $1-10 \%$ for the EMG 1200, EMG 1300 and EMG 1400 ferrofluids.

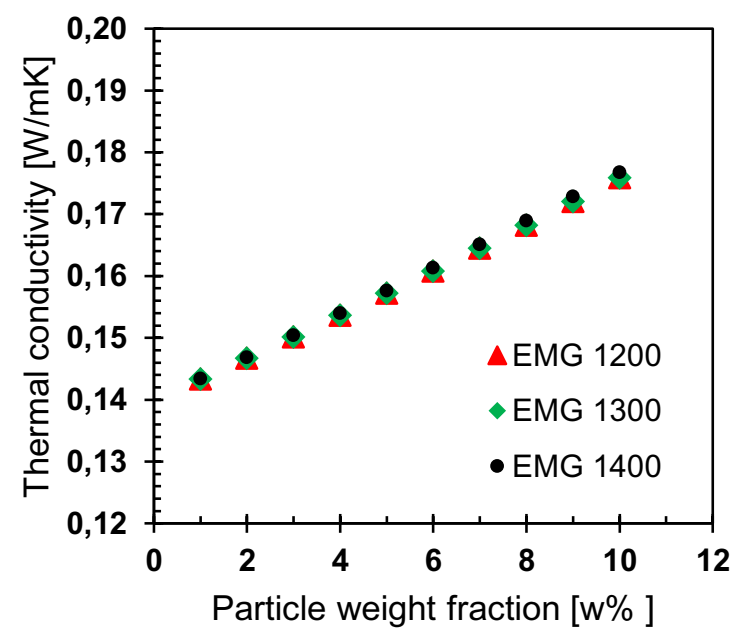

Figure 1: Calculated thermal conductivity for EMG 1200, EMG 1300 and EMG 1400 as a function ofironoxide particle weight concentration in percent.

Based on equation 2, Figure 1 shows a linear increase in calculated thermal conductivity for the three ferrofluids with only a slightly higher thermal conductivity of $0.144 \mathrm{~W} \cdot \mathrm{m}^{-1} \cdot \mathrm{K}^{-1}$ for EMG1400 compared to $0.143 \mathrm{~W} \cdot \mathrm{m}^{-1} \cdot \mathrm{K}^{-1}$ for EMG 1200 and EMG 1300 at $1 \%$ ofIron-oxide particle weight phase fraction. These results are in good agreement with experimental measurements reporting thermal conductivity for iron-oxide ferrofluids with up to $25 \%$ particle weight fraction [17]. 
Table 1: Properties of EMG 1200, EMG 1300 and $E M G$ 1400 ferrofluids.

\begin{tabular}{lccc}
\hline Properties & $\begin{array}{c}\text { EMG } \\
\mathbf{1 2 0 0}\end{array}$ & $\begin{array}{l}\text { EMG } \\
\mathbf{1 3 0 0}\end{array}$ & $\begin{array}{l}\text { EMG } \\
\mathbf{1 4 0 0}\end{array}$ \\
\hline $\begin{array}{l}\text { Iron-oxide content in dry } \\
\text { particles [\%] }\end{array}$ & 70 & 70 & 80 \\
$\begin{array}{l}\text { Particle weight phase } \\
\text { fraction [\%] }\end{array}$ & 1 & 1 & 1 \\
$\begin{array}{l}\text { Calculated thermal } \\
\left.\text { conductivity [W.m }{ }^{-1} \cdot \mathrm{K}^{-1}\right]\end{array}$ & 0.143 & 0.143 & 0.144 \\
$\begin{array}{l}\text { Surfactant [-] } \\
\text { Fatty }\end{array}$ & $\begin{array}{l}\text { Poly- } \\
\text { acid }\end{array}$ & $\begin{array}{l}\text { Hydro- } \\
\text { phobic }\end{array}$ \\
\hline
\end{tabular}

As can be seen from the properties of EMG 1200, EMG 1300 and EMG 1400 ferrofluids in Table 1, the slightly higher thermal conductivity with EMG 1400 stems from higher Iron-oxidecontent of $80 \%$ compared to $70 \%$ with EMG 1200 and EMG 1300. Due to the lack of information on the exact molecule structure of the surfactants employed, it is assumed that the fatty acid-, polymeric- and hydrophobic-surfactants have an identical thermal conductivity.

For the evaporation and condensation, the glass capillaries where filled with the EM G 1200, EM G 1300 and EM G 1400 ferrofluid and heated with a hot plate to $115{ }^{\circ} \mathrm{C}$ together with a pure heptane filled capillary as reference.

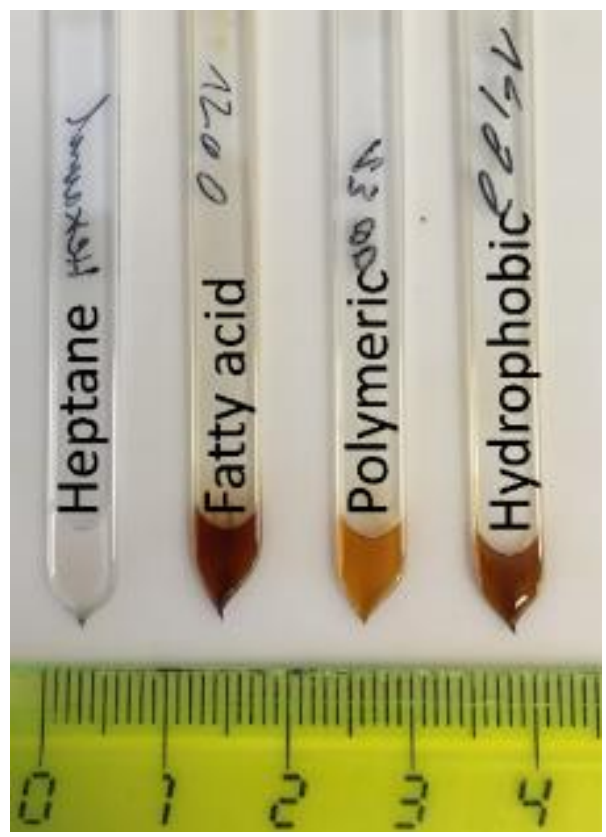

Figure 2a: (l-r) Pure n-Heptane capillary as reference, sonicated ferrofluid EMG 1200 in capillary, -ferrofluid EMG 1300 in capillary, and -ferrofluid EMG 1400 in capillary at room temperature,

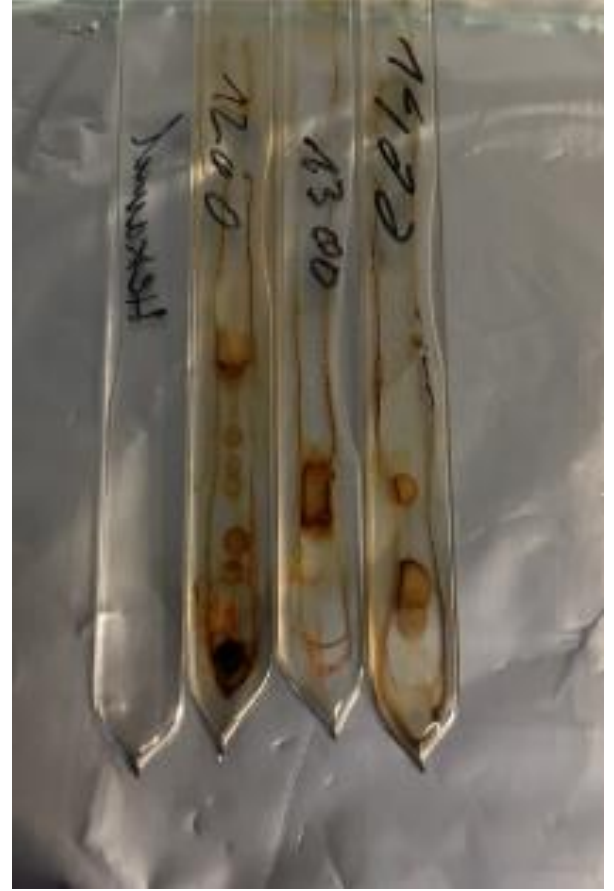

Figure 2b: Ferrofluids at $115^{\circ} \mathrm{C}$

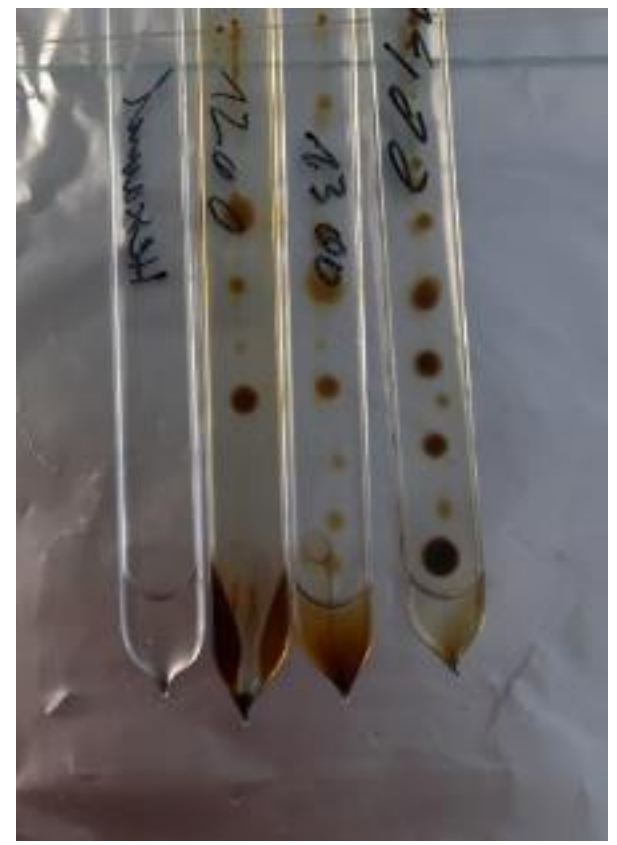

Figure 2c: Ferrofluids after condensation at room temperature at $1 \mathrm{w} \%$ in capillaries.

Figure 2 (a) shows from left (1) to right (r)the capillaries filled with the sonicated ferrofluid EMG 1200, ferrofluid EMG 1300, ferrofluid EMG 1400 and pure Heptane for reference. Figure 2 (b) shows the capillaries heated to a temperature of $115^{\circ} \mathrm{C}$. At $115^{\circ} \mathrm{C}$, the Heptane carrier fluid has evaporated leaving a particle sludge along the capillary. Figure 2 (c) shows the ferrofluid at room temperature after the Heptane carrier fluid condensed. According to Figure 2 (c), the ferrofluid EMG 1200 with the fatty acid surfactant shows good dispersion and therefore good mixing after condensation. Compared to 
the EMG 1200, the ferrofluid EMG1300 with a polymeric surfactant and the condensed EMG 1400 with a hydrophobic surfactant shows adistinct separation between the heptane carrier fluid and the particle sludge compared to Figure 2 (a). As an example, oleic acid is a fatty acid compound and is commonly used in iron-oxide nanoparticles creating a chelate bond with the iron atoms, which is stronger than a simple physisorption and subsequently survives higher temperatures [18]. For the demonstrated polymeric and hydrophobic surfactants in EMG 1300 and EMG 1400 aggregation took place during evaporation. If the surfactant molecules are weakly bonded to the particles, their desorption from the particles is already apparent at slightly elevated temperatures thus causing aggregation during evaporation.

\section{Conclusions}

Ferrofluid surfactants are crucial to the interaction between the particles in the fluids. This paper investigated the different surfactants for iron-oxide ferromagnetic particles and shows different surfactants impact upon the thermal properties of the ferrofluid. $W$ ith respect to thermal evaporation a fatty acid surfactant shows dispersion after condensation indicating good mixing of ferrofluid particles. In contrast, polymeric and hydrophobic surfactant ferrofluids show agglomeration of the particles and separation between the condensate and the particle sludge. Future work requires the chemical composition of the surfactant molecules to be known so that the bonding mechanism between the surfactant and the particles can be ascertained.

\section{References}

1. Kandlikar SG, Colin S, Peles Y, Garimella S, Pease RF, B randner JJ, Tuckerman DB. Heat transfer in microchannels-2012 status and research needs. Journal of Heat Transfer. 1;135(9):091001,(2013).

2. Kosterec M, Kurimský J, Cimbala R, Čonka Z, Kruželák L, Rajňák M, Timko M, Kopčanský P, Vargová B. Analysis of Thermal Field in Mineral Transformer Oil Based Magnetic Fluids. ActaPhysicaPolonica A. 1;131(4):937-9, (2017).

3. Raj K, Moskowitz R. Commercial applications of ferrofluids. Journal of Magnetism and Magnetic Materials. 1990 1;85(1-3):233-45, (1990).

4. Rosensweig RE. Fluid dynamics and science of magnetic liquids. InAdvances in electronics and electron physics, Vol. 48, pp. 103-199). Academic Press. (1979).

5. Popplewell J, Al-Q enaie A, Charles SW, M oskowitz $\mathrm{R}$, Raj K. Thermal conductivity measurements on ferrofluids. Colloid and Polymer Science, 260(3):333-8, (1982).

6. Raffa P, Wever DA, Picchioni $F$, Broekhuis AA. Polymeric surfactants: synthesis, properties, and links to applications. Chemical reviews, 16;115(16):8504-63 (2015).
7. www.ferrofluid.ferrotec.com/technology [Accessed: 30.08.2010].

8. Incropera FP, Lavine AS, B ergman TL, DeW itt DP. Fundamentals of heat and mass transfer. Wiley; (2007).

9. Jaworski M, Rusowicz A, Grzebielec A. Temperature stabilization in buildings by the use of heat/cold storage units with PCM integrated with the ventilation system. Inżynieria Bezpieczeństwa Obiektów Antropogenicznych, 3:31-37 (2019)

10. Chhabra RP, Richardson JF. Non-N ewtonian flow in the process industries: fundamentals and engineering applications. Butterworth-Heinemann; (1999).

11. Pietrak K, Wiśniewski TS. A review of models for effective thermal conductivity of composite materials. Journal of Power Technologies, 23;95(1):14-24, (2014

12. Hong TK, Y ang HS, Choi CJ. Study of the enhanced thermal conductivity of $\mathrm{Fe}$ nanofluids. Journal of Applied Physics, 97(6):064311, (2005).

13. Li M, Endo R, Akoshima M, Tanei H, Okada $H$, Susa M. Thermal Conductivity of Oxide Scale Thermally Grown on Iron Substrate Corrected by Temperature-dependent Interfacial Thermal Resistance in Laser Flash Measurement. ISIJ International.;59(3):398-403.(2019)

14. Lenin R, Joy PA. Role of base fluid on the thermal conductivity of oleic acid coated magnetite nanofluids. Colloids and Surfaces A: Physicochemical and Engineering Aspects;529:9229, (2017).

15. A ssael MJ, Bogdanou I, M ylona SK, Huber M L, Perkins RA, V esovic V. Reference Correlation of the Thermal Conductivity of $\mathrm{n}$ - $\mathrm{H}$ eptane from the Triple Point to $600 \mathrm{~K}$ and up to $250 \mathrm{M} \mathrm{Pa}$. Journal of Physical and Chemical Reference;42(2):023101, (2013).

16. Altan CL, Elkatmis A, Yüksel M, Aslan N, Bucak S. Enhancement of thermal conductivity upon application of magnetic field to $\mathrm{Fe} 304$ nanofluids. Journal of Applied Physics.;110(9):093917, (2011).

17. Fertman VE, Golovicher LE, M atusevich NP. Thermal conductivity of magnetite magnetic fluids. Journal of Magnetism and Magnetic M aterials.;65(2-3):211-4, (1987).

18. Soares PI, Alves AM, Pereira LC, Coutinho JT, Ferreira IM, Novo CM, Borges JP. Effects of surfactants on the magnetic properties of iron oxide colloids. Journal of colloid and interface science.;419:46-51, (2014). 